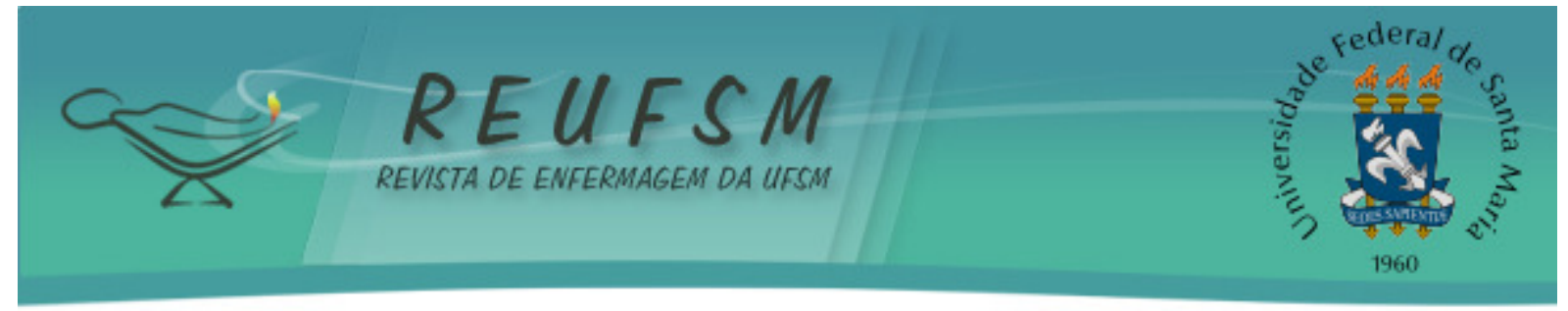

\title{
REPRESENTAÇÕES SOCIAIS DE MULHERES MIGRANTES DA MESMA FAMÍLIA E DE DIFERENTES GERAÇÕES SOBRE AMAMENTAÇÃO
}

\section{SOCIAL REPRESENTATIONS OF MIGRANT WOMEN OF THE SAME FAMILY AND OF DIFFERENT GENERATIONS ON BREASTFEEDING}

\section{REPRESENTACIONES SOCIALES DE MUJERES MIGRANTES DE LA MISMA FAMILIA Y DE DIFERENTES GENERACIONES SOBRE AMAMANTAMIENTO}

\author{
Michelle Araújo Moreira ${ }^{1}$ \\ Polliana Santos Ribeiro ${ }^{2}$ \\ Jéssica Suellen Barbosa Mendes Ramos ${ }^{3}$ \\ Marcella Bonifácio Lelles Dias ${ }^{4}$ \\ Juliana Oliveira de Castro ${ }^{5}$
}

Doi: $10.5902 / 2179769226544$

RESUMO: Objetivo: analisar as representações sociais de mulheres migrantes da mesma família e de diferentes gerações sobre amamentação. Método: estudo qualitativo fundamentado na Teoria das Representações Sociais, realizado no município de Ilhéus-Ba, entre março e maio de 2016. Os dados foram obtidos pelo Teste de Associação Livre de Palavras (TALP) com 21 tríades selecionadas na modalidade Snowball, sendo analisados pelo software Ensemble de Programmes Permettant L'analyse des Évocations (EVOC). Resultados: para as migrantes, a amamentação é representada como uma prática de nutrição que contribui para o desenvolvimento físico e afetivo do filho. $\mathrm{O}$ processo de ensinoaprendizagem centra-se na figura materna e a rede de apoio é simbolizada pela avó, mas ampliada aos pais e maridos. Conclusões: torna-se necessário compreender as dimensões geográficas, culturais e sociais da amamentação no intuito de oferecer uma assistência qualificada e humanizada às migrantes.

Descritores: Aleitamento materno; Relação entre gerações; Migração; Saúde da mulher; Enfermagem.

ABSTRACT: Aim: to analyze the social representations of female migrants from the same family and from different generations about breastfeeding. Method: a qualitative study based on the Theory of Social Representations, carried out in the city of Ilhéus-Ba, between March and May 2016. The data were obtained by the Free Word Association Test (TALP) with 21 triads selected in the Snowball modality. Software Ensemble of Permettant Programs L'analyze des Évocations (EVOC) was used to analyse the data. Results: for the migrants, breastfeeding is represented as a nutrition practice that contributes to the physical and affective development of the child. The teaching-learning process focuses on the maternal figure and the support network is symbolized by the grandmother, but extended to the parents

\footnotetext{
${ }^{1}$ Enfermeira, Pós-doutora em Enfermagem, Universidade Estadual de Santa Cruz, Ilhéus, Bahia, Brasil. E-mail: michelleepedro@uol.com.br.

${ }^{2}$ Enfermeira, Universidade Estadual de Santa Cruz, Ipiaú, Bahia, Brasil. E-mail: pollyribeir@hotmail.com.

3 Graduanda em Enfermagem, Universidade Estadual de Santa Cruz, Ilhéus, Bahia, Brasil. E-mail: jsuellen7@gmail.com.

${ }_{4}$ Graduanda em Enfermagem, Universidade Estadual de Santa Cruz, Itabuna, Bahia, Brasil. E-mail: malelles@gmail.com.

${ }^{5}$ Graduanda em Enfermagem, Universidade Estadual de Santa Cruz, Itabuna, Bahia, Brasil. E-mail: julianacastro660@hotmail.com.
} 


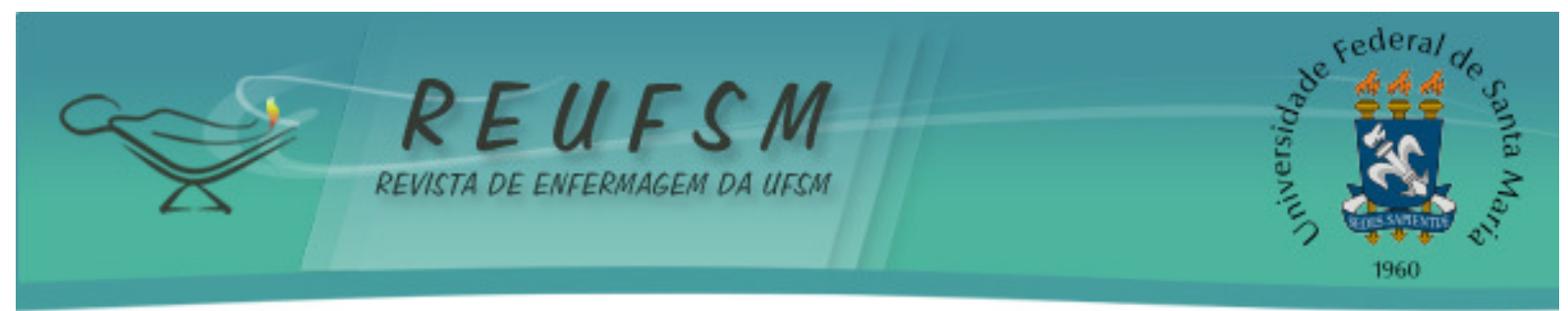

(or fathers) and husbands. Conclusions: it is necessary to understand the geographical, cultural and social dimensions of breastfeeding in order to offer qualified and humane assistance to migrants.

Descriptors: Breast feeding; Intergenerational relations; Migration; Women's health; Nursing.

RESUMEN: Objetivo: analizar las representaciones sociales de mujeres migrantes de la misma familia y de diferentes generaciones sobre amamantamiento. Método: estudio cualitativo fundamentado en la Teoría de las Representaciones Sociales, realizado en el municipio de Ilhéus-Ba, entre marzo y mayo de 2016. Los datos fueron recolectados por medio de la Prueba de Asociación Libre de Palabras (TALP) con 21 tríadas seleccionadas en la modalidad Snowball, El programa Ensemble de los programas permettant L'analyse des Évocations (EVOC). Resultados: para las migrantes el amamantamiento representa una práctica de nutrición que contribuye para el desarrollo físico y afectivo del hijo. El proceso de enseñanza-aprendizaje se centra en la figura materna y la red de apoyo es simbolizada por la abuela, pero ampliada a los padres y maridos. Conclusiones: es necesario comprender las dimensiones geográficas, culturales y sociales del amamantamiento con el objetivo de ofrecer asistencia cualificada y humanizada a las migrantes.

Descriptores: Lactancia materna; Relaciones intergeneracionales; Migración; Salud de la mujer; Enfermería.

\section{INTRODUÇÃO}

A amamentação representa uma prática sociocultural influenciada por fatores econômicos, políticos, ideológicos, familiares e geracionais, que precisa ser desenvolvida em diferentes contextos e em condições físicas e emocionais satisfatórias. A construção do saber e do fazer no processo da amamentação ocorre, prioritariamente, no espaço doméstico, ancorado por múltiplas experiências entre mulheres da mesma família e de diferentes gerações. ${ }^{1-2}$

Sendo assim, as vivências entre nutrizes, suas mães, avós e/ou outras mulheres com proximidade afetiva, somam-se aos conhecimentos sobre a amamentação, ofertados pelos profissionais de saúde e pela mídia. Tal interação contribui para a formação de redes de solidariedade ou conflito entre as diferentes gerações com desvelamento sobre suas simbologias.

Nesse sentido, evidencia-se que as representações sociais sobre a amamentação nas distintas gerações podem sofrer modificações. Mulheres que vivenciaram o processo de migração geográfica e/ou afetiva, por exemplo, podem apresentar novos constructos sobre a amamentação no meio familiar e relacional. ${ }^{3}$

Sabe-se que a amamentação favorece a proteção e o desenvolvimento físico e cognitivo do bebê, além de contribuir na vinculação afetiva entre mãe-filho com apoio da rede intrafamiliar. 


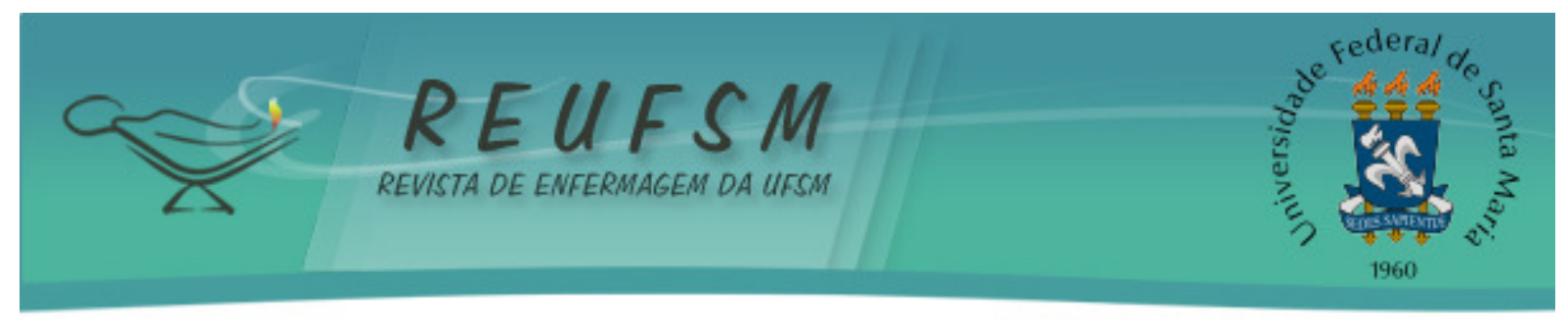

Para tanto, as gerações aprendem sobre essa e outras simbologias do ato de amamentar em um movimento dialético de continuidade ou descontinuidade de normas, condutas e tabus. ${ }^{4}$

Outro fator importante refere-se à coexistência e coabitação, cada vez mais frequente, entre diferentes gerações de mulheres que migraram na modalidade intermunicipal e interestadual e amamentaram independentemente do tempo e da quantidade de filhos, oportunizando que existam influências familiares positivas e/ou negativas sobre a prática do aleitar, com base na construção social, histórica e política que tiveram em cada tempo social. Sabe-se que o envelhecimento da população brasileira amplia a proximidade entre as gerações e que o deslocamento geográfico e afetivo do local de origem para o local de acolhimento em busca de novas oportunidades para a melhoria da qualidade de vida, permite que as mulheres migrantes e de gerações distintas possam se ajudar mutuamente na experiência da amamentação.

Portanto, a interferência, o apoio e o incentivo familiar constituem os princípios que regulamentam o comportamento e as representações de mulheres migrantes durante a amamentação dos seus filhos. Estas atitudes, oriundas do contexto familiar, pode fazê-las manter a prática ou suspendê-la, com base nas relações de poder e afeto que são instituídas entre as gerações predecessoras e sucessoras. ${ }^{1}$

Com isso, justifica-se a importância do estudo pelo fato deste minimizar a insuficiência de publicações nacionais e/ou internacionais sobre a amamentação na perspectiva migratória e intergeracional, tendo em vista que a maioria das pesquisas restringe-se a uma ou duas gerações, nesse caso, retratadas apenas como mãe e filho. Além disso, os estudos produzidos sobre a temática concentram-se, majoritariamente, nos aspectos epidemiológicos, nos benefícios do aleitamento para mãe e criança, nas causas de desmame precoce, nas iniciativas de incentivo à amamentação, nas dificuldades maternas que inviabilizam o processo de amamentar, dentre outros, mas poucos se dedicam a aprofundar as representações parentais e migratórias sobre a amamentação envolvendo três gerações diferentes.

Nota-se uma dificuldade no desenvolvimento de pesquisas que abordem sobre a experiência de amamentar a partir dos constructos das próprias mulheres, desconsiderando suas dissonâncias e consonâncias intergeracionais. Observa-se, ainda, que as investigações que envolvem o processo migratório não tratam da amamentação e não costumam utilizar técnicas e métodos projetivos de coleta e análise dos dados, a exemplo do Teste de Associação Livre de Palavras (TALP) e do software Ensemble de Programmes Permettant 


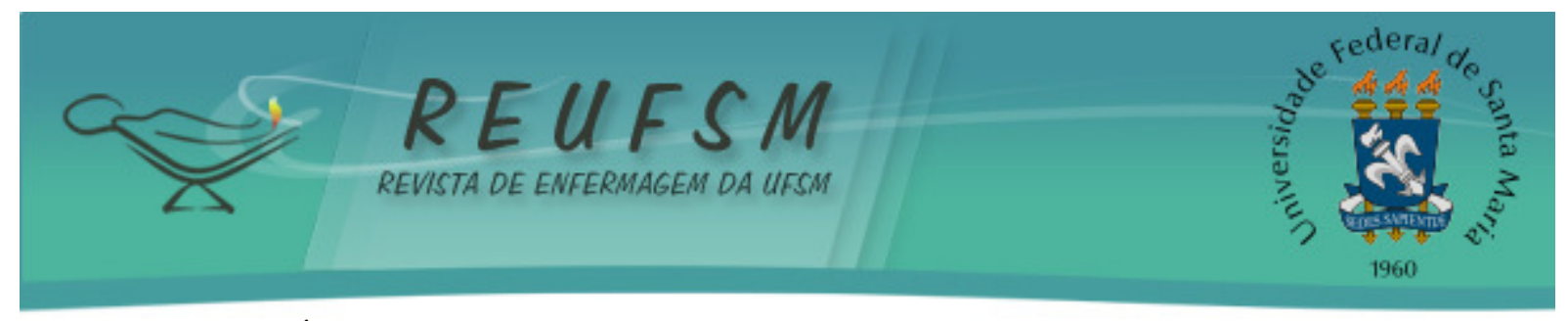

L'analyse des Évocations (EVOC) que permitem valorizar as significações sociais de mulheres migrantes no ambiente familiar., ${ }^{2,5}$

Desse modo, tem-se a seguinte questão de pesquisa: Quais as representações sociais de mulheres migrantes e de gerações distintas sobre amamentação? Diante disto, definiu-se como objetivo deste estudo: analisar as representações sociais de mulheres migrantes da mesma família e de diferentes gerações sobre amamentação.

\section{MÉTODO}

Trata-se de um estudo qualitativo, fundamentado na Teoria das Representações Sociais no que se refere à abordagem estrutural. A teoria das representações sociais aborda o contexto das relações sociais, o convívio com as múltiplas subjetividades culturais e as atitudes, os discursos, os pensamentos e os sentimentos dos sujeitos que definem uma prática ou objeto. ${ }^{6}$

As participantes foram 63 mulheres, ou seja, 21 tríades. A seleção das depoentes foi realizada na modalidade Snowball (Bola de Neve), ou seja, as participantes iniciais do estudo indicavam novas participantes e assim sucessivamente, até que foi alcançado o ponto de saturação dos conteúdos obtidos.

Os critérios de inclusão das participantes foram: ter filha e neta ( $1^{\mathrm{a}}$ geração)/mãe e filha ( $2^{\mathrm{a}}$ geração)/mãe e avó materna ou paterna ( $3^{\mathrm{a}}$ geração) que amamentaram ou amamentam, independentemente do tempo de amamentação e da quantidade de filhas(os); residir no município de Ilhéus ou em cidades do entorno; ter migrado internamente no país (de uma região para outra, de um estado para outro, de um município para outro) ou ter migrado na modalidade internacional na condição voluntária (vindo de outro país); possuir laço de consanguinidade e/ou afetividade com as mulheres da mesma família e de gerações diferentes, a exemplo de mãe adotiva, avó adotiva ou sogra); ter convivência (viver em proximidade) com as mulheres da mesma família e de diferentes gerações (no mesmo espaço geográfico ou em lugares diferentes); ter situação de migração em, pelo menos, uma geração de mulheres da mesma família. Consequentemente, os critérios de exclusão foram: ser um refugiado; não ter capacidade civil plena; não ter amamentado; ter migrado na modalidade de domicílio (de um domicílio para outro); ter uma convivência esporádica (conviver irregularmente, ou seja, um encontro por mês ou por ano) entre as mulheres da mesma família. 


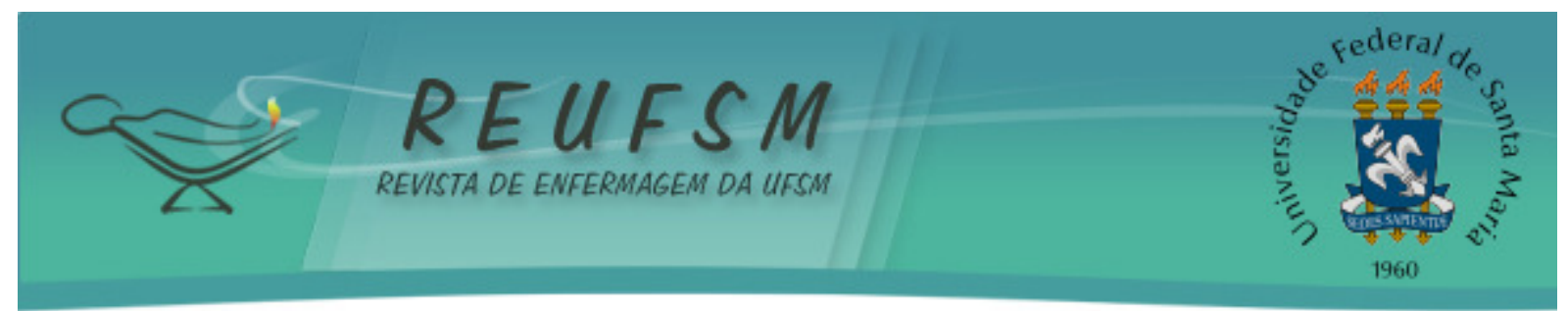

O estudo foi realizado no município de Ilhéus-Bahia. A escolha por esta cidade caracterizou-se por ser local constante de migração para as mulheres de outros países, regiões, estados e municípios juntamente com seus familiares, incluindo as mães e/ou filhas/os, que passaram ou passam pela experiência da amamentação.

Objetivando atingir as propriedades quantitativas e qualitativas para determinar a estrutura da representação social, por meio do núcleo central e sistema periférico, foi utilizada a TALP. As técnicas projetivas tornam a estrutura psicológica dos sujeitos palpável, por meio das reações, evocações e criações, pois se utilizam das simbologias sobre determinados estímulos que são aplicados na pesquisa para obter respostas dos sujeitos, fazendo emergir o que se apresenta latente à consciência. As técnicas projetivas permitem o desvelamento e o desencobrimento das representações sociais que os indivíduos têm de si, do mundo circundante e daqueles que interage no cotidiano. $^{7}$

Para a aplicação da TALP, foi entregue uma folha de resposta específica, contendo os seguintes estímulos indutores, por meio da expressão: Diga-me cinco palavras que vêm imediatamente a sua mente quando eu falo: "amamentação", "com quem aprendeu sobre amamentação" e "apoio da família na amamentação", referente à primeira, segunda e terceira geração e solicitado às depoentes que preenchessem individualmente e na impossibilidade de efetuarem o registro por inexistência ou precária escolarização, este foi feito pelas pesquisadoras.

A coleta dos dados foi realizada nos domicílios, entre março e maio de 2016, em dia e horário determinados pelas depoentes, mediante orientação prévia sobre os objetivos da pesquisa, os procedimentos de coleta dos dados, a livre decisão em participar ou não do estudo, com posterior assinatura do termo de consentimento. Convém destacar que os aspectos éticos permearam toda a elaboração e desenvolvimento desta pesquisa.

Nesse sentido, encaminhou-se o projeto para avaliação do Comitê de Ética em Pesquisa da Universidade Federal da Bahia, pautado nos princípios éticos da pesquisa que envolve seres humanos, definidos e regulamentados na Resolução n 466/12, do Conselho Nacional de Saúde. O projeto foi aprovado em 21 de março de 2016, sob número de parecer 1.459.882.

Posteriormente, o produto decorrente da TALP foi organizado por similaridade semântica, processado e analisado com o apoio do software EVOC. Destaca-se que a coleta feita pela TALP e posterior análise dos dados demonstra a perspectiva qualitativa ao buscar as evocações dos participantes frente aos estímulos indutores, ou seja, as representações do inconsciente de 


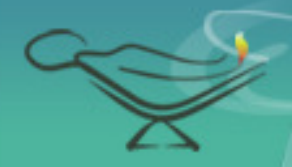

mulheres migrantes sobre a amamentação e, ao mesmo tempo, demonstrar a importância dos achados em frequências. Esse programa calcula a frequência (Freq) simples de cada palavra evocada, a ordem média de evocação (OME) e a média das ordens médias de palavras evocadas, permitindo a análise lexicográfica mediante a técnica do Quadro de Quatro Casas que representa o Núcleo Central e os elementos periféricos da representação sobre a amamentação.

\section{RESULTADOS E DISCUSSÃO}

Para o estímulo amamentação (Quadro 1), registrou-se 66 termos diferentes para um total de 315 evocações, garantindo 84,4\% de aproveitamento. No que se refere ao estímulo com quem aprendeu sobre amamentação (Quadro 2), detectou-se 58 termos diferentes, deflagrando $81,3 \%$ de aproveitamento. Por fim, o estímulo apoio da família na amamentação (Quadro 3) obteve 102 termos diferentes, resultando em 74,6\% de aproveitamento, conforme evidenciados a seguir:

\begin{tabular}{|c|c|c|c|c|c|c|}
\hline OME & & & & & & \\
\hline Freq. Média & Termo evocado & Freq & & Termo evocado & Freq & OME \\
\hline \multirow[t]{4}{*}{$\geq 13$} & Amor & 43 & 2,698 & Alimentação & 18 & 3,333 \\
\hline & Saúde & 28 & 2,643 & Carinho & 34 & 3,147 \\
\hline & & & & Dor & 13 & 3,231 \\
\hline & & & & Prazer & 19 & 3,105 \\
\hline \multirow[t]{9}{*}{$<13$} & Afeto & 8 & 3,000 & Crescimento & 5 & 4,200 \\
\hline & Alegria & 6 & 2,500 & Vínculo & 9 & 3,222 \\
\hline & Bom & 5 & 2,400 & & & \\
\hline & Cuidado & 6 & 2,833 & & & \\
\hline & Dificuldades & 5 & 1,600 & & & \\
\hline & Doação & 5 & 2,800 & & & \\
\hline & Leite & 11 & 1,455 & & & \\
\hline & Peito & 5 & 3,000 & & & \\
\hline & Proteção & 5 & 3,000 & & & \\
\hline
\end{tabular}

Quadro 1 - Quadro de quatro casas com explanação ao termo indutor "amamentação". Ilhéus, BA, Brasil, 2017.

Os dados exibidos no Quadro 1 permitem apontar que o núcleo central sobre a amamentação entre mulheres migrantes, evidenciado no quadrante superior à esquerda, demonstra que essa prática é representada como uma prova de amor e, ao mesmo tempo, de promoção da saúde infantil, seja no aspecto biológico, cognitivo e/ou emocional. Estudos revelam que o constructo social da amamentação enquanto ato de amor permanece atrelado às campanhas de incentivo ao aleitamento exclusivo, reafirmando a ideia da mulher como a principal provedora de alimento e afeto para seu bebê. Tal simbologia contribui para arraigar 


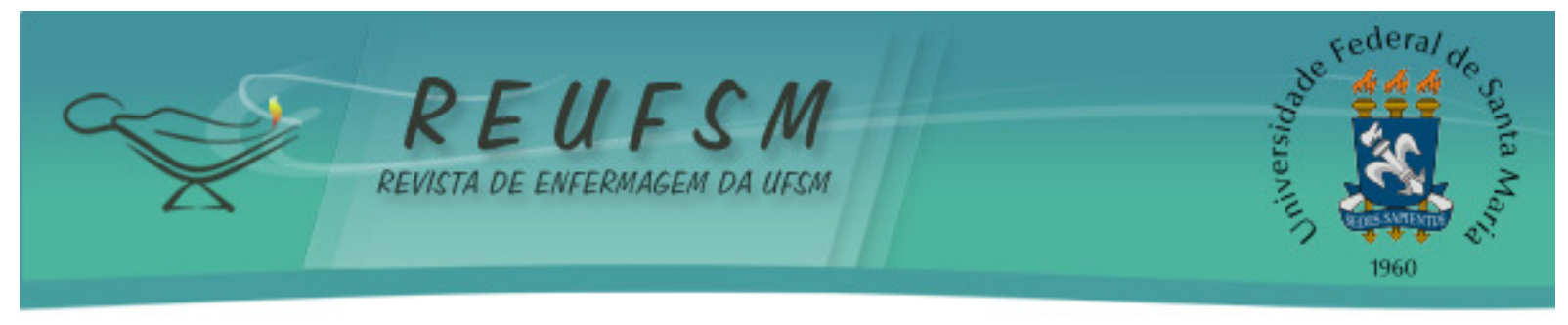

a amamentação como algo inerente e obrigatório da maternidade, resultando em culpa entre as mulheres que não possuem condições de aleitar seus filhos por fatores biológicos, socioculturais, econômicos, geográficos e ideológicos. ${ }^{2,8-9}$

Nesse sentido, torna-se necessário compreender que cada mulher migrante traz, em suas experiências e narrativas, elementos da cultura, sonhos, projetos e memórias, buscando sua identidade e tornando-se sujeito dos seus próprios atos. ${ }^{10}$ Portanto, o processo migratório e intergeracional podem influenciar nos significados de aleitar, muitas vezes, permeados por crenças, valores, mitos e tabus construídos culturalmente em período e ambientes distintos. ${ }^{2,11}$

Por sua vez, o quadrante superior à direita correspondente aos elementos da primeira periferia, ou seja, que corroboram com as evocações do núcleo central com menor frequência e maior ordem média de evocação (OME). Este quadrante demonstra que as representações sociais sobre a amamentação entre mulheres migrantes, correspondem a um processo que contribui no desenvolvimento da criança, proporcionando carinho e prazer, embora algumas relatem simbologias negativas, a exemplo da dor.

A dor costuma ser fisiológica nos primeiros dias de adaptação pós-parto, mas pode vir acompanhada de dificuldade, o que resulta, muitas vezes, em desmame precoce. Assim, faz-se necessário que as(os) profissionais de saúde orientem as mães a prevenir e/ou aliviar tais intercorrências. $^{11-12}$

Ademais, a amamentação em situações de migração pode se constituir em vulnerabilidade social, decorrente do afastamento de alguns familiares, do deslocamento espacial, da ausência ou insuficiência de informações sobre as peculiaridades culturais da região, o que pode gerar insegurança e temor. Tudo isso pode resultar em conflitos e sentimentos ambíguos na relação mãe-bebê e seus descendentes, evidenciando a necessidade de acolhimento. ${ }^{13}$

Somado a isso, no quadrante inferior à direita, relativo à segunda periferia, cujos elementos são menos frequentes e com maior OME, percebe-se que, para as migrantes, a amamentação é um mecanismo puramente nutricional que proporciona um crescimento adequado para a criança, além de que a mãe pode oferecer aconchego, proporcionando, assim, momentos de proximidade diária. ${ }^{14-15}$

No quadrante inferior à esquerda, onde estão presentes os elementos de contraste com menor frequência, fica claro que ao amamentar, o filho pode despertar à mãe um sentimento de doação, intensificando o laço afetivo que pode resultar em alegria, aliada à proteção e 
cuidado. Dessa forma, as múltiplas representações sobre a amamentação podem contribuir na saúde do bebê, momento em que a migrante oferece o peito para alimentar, apesar das problemáticas que permeiam o processo, a exemplo da dor. ${ }^{16}$

É imprescindível compreender que o processo migratório aliado à prática da amamentação pode resultar em conflitos internos relacionados à existência de dois códigos culturais em locais diferentes, por vezes, contraditórios e incompreensíveis, acarretando em um efeito desorganizador nas mulheres migrantes. ${ }^{9}$ Portanto, o apoio familiar e o suporte dos profissionais de saúde na cultura de acolhimento tornam-se fundamentais para superar as dificuldades no decorrer da amamentação, diminuindo o estresse de aculturação. ${ }^{13}$

No que se refere ao Quadro 2, nota-se que as evocações relacionadas ao aprendizado na amamentação, presentes no quadrante superior esquerdo, trazem a figura materna como centro do processo de aprendizagem. Além disso, as mulheres migrantes valorizam o papel dos profissionais de saúde e a influência midiática na ampliação do conhecimento sobre o amamentar.

\begin{tabular}{|c|c|c|c|c|c|c|}
\hline OME & & & & & & \\
\hline Freq.Média & Termo evocado & Freq & OME & Termo evocado & Free & OME \\
\hline$\geq 16$ & Mãe & 51 & 1,627 & Avó & 20 & 3,100 \\
\hline & Médico & 19 & 2,737 & & & \\
\hline & Televisão & 17 & 2,882 & & & \\
\hline$<16$ & Experiência & 15 & 3,000 & Amigas & 13 & 3,923 \\
\hline & Família & 11 & 2,818 & Amor & 4 & 4,250 \\
\hline & Hospital & 4 & 2,500 & Enfermeira & 7 & 3,143 \\
\hline & Instinto & 4 & 2,500 & Escola & 6 & 3,667 \\
\hline & Leituras & 11 & 2,909 & Filho & 6 & 3,833 \\
\hline & Sozinha & 11 & 1,909 & Internet & 7 & 3,429 \\
\hline & & & & Irmã & 11 & 4,273 \\
\hline & & & & Observando & 5 & 3,200 \\
\hline & & & & Revistas & 4 & 3,750 \\
\hline & & & & Tia & 13 & 3,923 \\
\hline & & & & Vida & 6 & 3,167 \\
\hline & & & & Vizinha & 11 & 3,455 \\
\hline
\end{tabular}

Quadro 2 - Quadro de quatro casas com explanação ao termo indutor "com quem aprendeu sobre amamentação". Ilhéus, BA, Brasil, 2017.

Sabe-se que a prática da amamentação desenvolve-se, inicialmente, no ambiente doméstico e familiar, sendo reservada a mãe à responsabilidade pela passagem do conhecimento e dos valores relacionados à sua manutenção, demonstrando o caráter disciplinador e de obediência construído ao longo da geração. ${ }^{17}$ Especialmente no período pós-parto, a convivência entre mãe e filha pode contribuir para movimentos de solidariedade ou de conflito no processo de amamentar, redefinindo simbologias. ${ }^{18}$ 


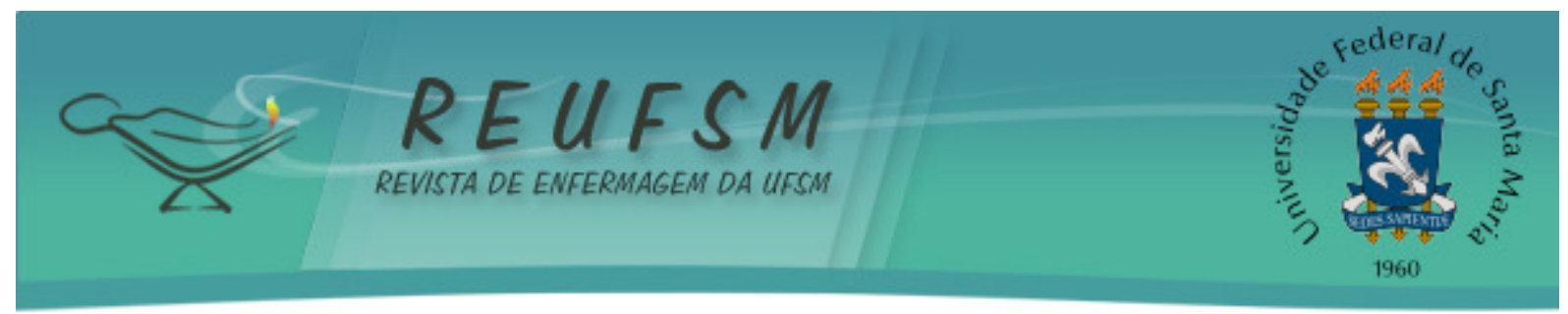

Dessa forma, as representações sobre amamentação passam a ser compartilhadas de maneira intergeracional. Logo, o material empírico adquirido pela geração predecessora é transmitido para as sucessoras, que podem modificá-lo ou mantê-lo ao longo do tempo. ${ }^{19}$

Além disso, sabe-se que a transmissibilidade de informações sobre a amamentação permanece atrelada aos fatores históricos, geográficos e socioculturais vividos em cada geração. Evidencia-se que as migrantes mais jovens procuram outras fontes e espaços de aprendizagem, para além da família.

Sendo assim, as(os) profissionais de saúde atuam como incentivadoras(es) para a continuidade da amamentação, devido ao conhecimento, ao acolhimento e à humanização dispensados às mulheres migrantes na assistência diária. Nota-se que enfermeiras(os) e médicos influenciam, na maioria dos casos, de forma positiva no aprendizado sobre a amamentação. ${ }^{1}$

Ademais, a influência midiática exerce poder sobre a prática da amamentação entre mulheres de diferentes gerações. Por um lado, as migrantes são expostas ao excesso de informações sem fontes confiáveis e pelas propagandas do uso de leites artificiais e, por outro lado, lidam com o incentivo massivo feito pelas(os) profissionais de saúde para a manutenção do aleitamento materno exclusivo, gerando conflitos no que tange ao conhecimento transmitido ao longo do processo de ser mãe. ${ }^{20}$ Evidencia-se que algumas gerações, situadas em determinadas regiões do país não viveram a forte expansão da tecnologia, o que as fez preservar as representações desenvolvidas nos espaços de convívio doméstico, enquanto outras gerações foram influenciadas precocemente pelas concepções midiáticas dentro e fora da família.

No que tange ao quadrante superior direito, que faz parte da primeira periferia e reforça o núcleo central, observa-se que a avó representa uma referência no conhecimento apreendido sobre a amamentação. A posição hierárquica e afetiva da avó dentro da família, além da sua experiência, proporciona que novas mães possam significar positivamente e/ou negativamente a maternidade e o cotidiano de aleitar. ${ }^{21}$

Por sua vez, o quadrante inferior direito, ou segunda periferia, apresenta os elementos com menor frequência e maior OME, que exercem função reguladora. ${ }^{22}$ Entende-se que tais evocações atuam como núcleo de apoio e informação da migrante, pois os laços afetivos formados ao longo do tempo e os exemplos servem como fonte de encorajamento para a mulher manter-se na prática da amamentação. Percebe-se, então, que a rede social de apoio pode favorecer essa manutenção, especialmente quando o conhecimento advém de pessoas 


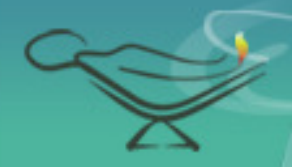

mais experientes e que, por vezes, não possuem laços de consanguinidade, e sim, relações de afetividade, a exemplo de amigos e vizinhas. ${ }^{23}$

Observa-se, ainda, que a enfermeira pode atuar na rede de incentivo à amamentação. Ela é responsável por todos os cuidados e orientações sobre as mamas e o bebê, demonstrando maior disponibilidade e eficiência nos serviços de acompanhamento. ${ }^{18}$

Por outro lado, verifica-se que a aprendizagem sobre a amamentação também decorre da observação, quer seja nas atividades educativas realizadas pelas(os) profissionais de saúde no pré-natal e/ou pós-parto, ou pela própria transmissibilidade efetuada pelas gerações. Notase, ainda, que as lactantes constantemente procuram na internet, em revistas, livros e cartilhas fornecidas pelo Ministério da Saúde (MS), meios de aprendizado sobre a amamentação. ${ }^{5}$

Acrescido a isso, o quadrante inferior esquerdo apresenta a zona de contraste, ou seja, os elementos que apresentaram menor frequência e OME que oferecem sustentação ao núcleo central. Visualiza-se, ainda, que algumas mulheres legitimam a amamentação como puramente instintiva e biológica, sendo algo vivido de maneira individual. Contudo, sabe-se que a amamentação sofre influência dos estímulos socioeconômicos e culturais entre as distintas gerações. ${ }^{17}$

Nessa linha de pensamento, o Quadro 3 demonstra, no quadrante superior esquerdo, que o apoio familiar na amamentação das migrantes ancora-se na presença materna. Tal importância dada à mãe relaciona-se ao fato de serem mulheres mais velhas e experientes, que atuam como alicerce para as mais inexperientes. Sabe-se que a prática da amamentação é desenvolvida de geração a geração, por meio do compartilhamento e troca de experiências entre mães e filhas.

\begin{tabular}{|c|c|c|c|c|c|c|}
\hline OME & \multicolumn{3}{|c|}{$<\mathbf{3 , 0}$} & \multicolumn{3}{|c|}{$\geq \mathbf{3 , 0}$} \\
\hline Freq.Média & Termo evocado & Freq & $\mathrm{OMH}$ & Termo evocado & Frea & OME \\
\hline \multirow[t]{4}{*}{$\geq 10$} & Mãe & 16 & 1,875 & Amor & 16 & 4,000 \\
\hline & & & & Apoio & 13 & 4,000 \\
\hline & & & & Carinho & 14 & 3,429 \\
\hline & & & & Incentivo & 11 & 3,091 \\
\hline \multirow[t]{9}{*}{$<10$} & Avó & 5 & 2,600 & Afeto & 6 & 3,167 \\
\hline & Bom & 7 & 1,857 & Ajuda & 9 & 3,556 \\
\hline & Conselho & 4 & 2,500 & Alimentação & 4 & 4,250 \\
\hline & Cuidado & 6 & 2,667 & Amigos & 5 & 3,200 \\
\hline & Ensinamento & 5 & 3,000 & & & \\
\hline & Importante & 9 & 1,556 & & & \\
\hline & Marido & 10 & 2,100 & & & \\
\hline & Muito & 5 & 1,000 & & & \\
\hline & Nenhuma & 5 & 1,000 & & & \\
\hline
\end{tabular}




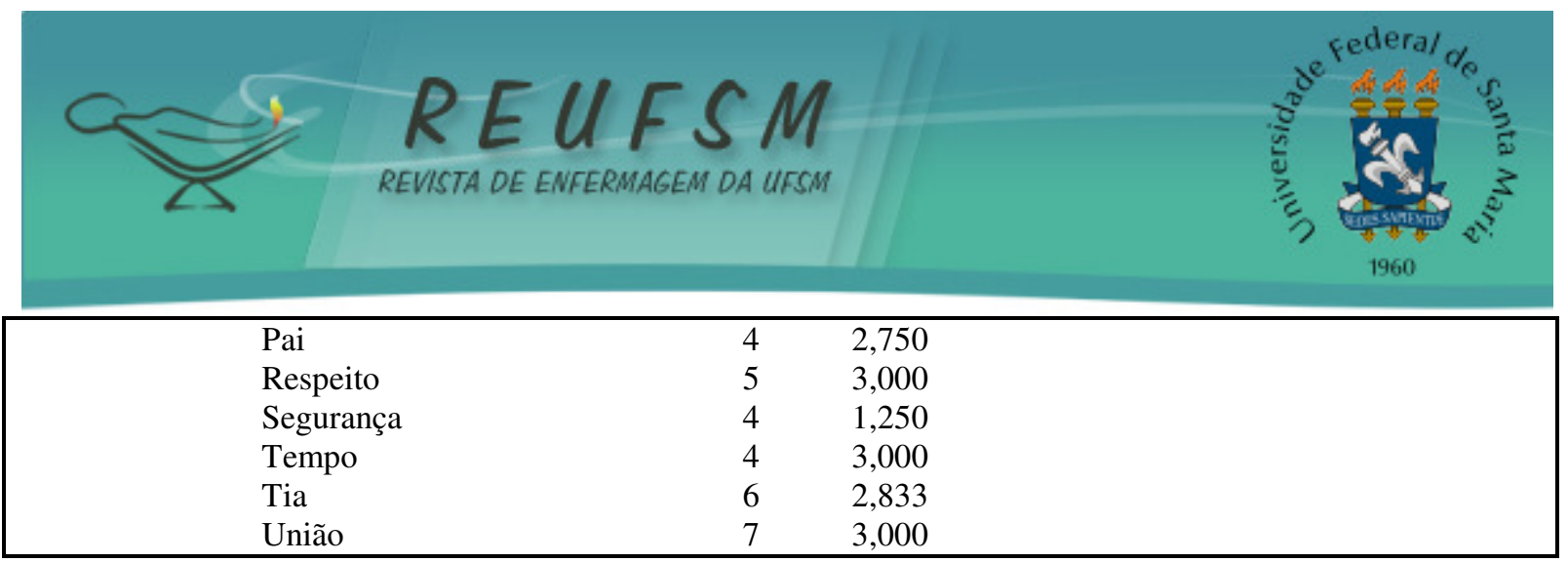

Quadro 3 - Quadro de quatro casas com explanação ao termo indutor "apoio da família na amamentação". Ilhéus, BA, Brasil, 2017.

No que tange às evocações do quadrante superior direito ou $1^{a}$ periferia, nota-se que a manutenção da amamentação entre migrantes acontece em decorrência do suporte ofertado por suas famílias, por meio do incentivo diário com expressão de carinho e amor. Assim, é possível ampliar os laços afetivos e minimizar os medos e angústias que podem surgir no decorrer desse processo. ${ }^{24}$

Por conseguinte, as evocações situadas no quadrante inferior direito apontam que o apoio na amamentação não advém apenas da família consanguínea, mas também do vínculo social estabelecido com amigos, demonstrando que essa ajuda desenvolve-se pelo afeto. Ademais, o apoio familiar é essencial para trocar ensinamentos entre as diferentes gerações, não apenas pelo vínculo de confiança existente, mas pelo fato da comunhão grupal satisfazer emocionalmente as migrantes mais inexperientes com a prática de amamentar.

Por último, o quadrante inferior esquerdo que corresponde às evocações menos frequentes e que corroboram com a $1^{\text {a }}$ periferia. Evidencia-se que o apoio familiar influencia de maneira distinta as mulheres migrantes no que tange à amamentação. Algumas o consideram como algo importante e bom, que proporciona união e que interfere nas formas de aleitar. Outras mulheres, por sua vez, consideram pouco representativo pelo fato de não possuírem a família próxima no cotidiano de amamentar.

Além disso, a avó é representada como a figura que transmite segurança por estar, a maior parte do tempo, inserida no contexto das relações familiares. Visualiza-se que as mulheres das gerações predecessoras transmitem o cuidado, os ensinamentos e os conselhos sobre a amamentação, interferindo significativamente para a sua manutenção.

Para as migrantes, a presença do seu pai e de outros familiares, a exemplo da tia, também contribuem para a continuidade da amamentação pela relação de confiança e respeito formada entre eles. Percebe-se, ainda, que a migrante valoriza a presença do marido no processo da amamentação, pois este serve como suporte nos momentos prazerosos e de dificuldades, revelando a importância do incentivo constante à participação dos homens. ${ }^{24}$ 


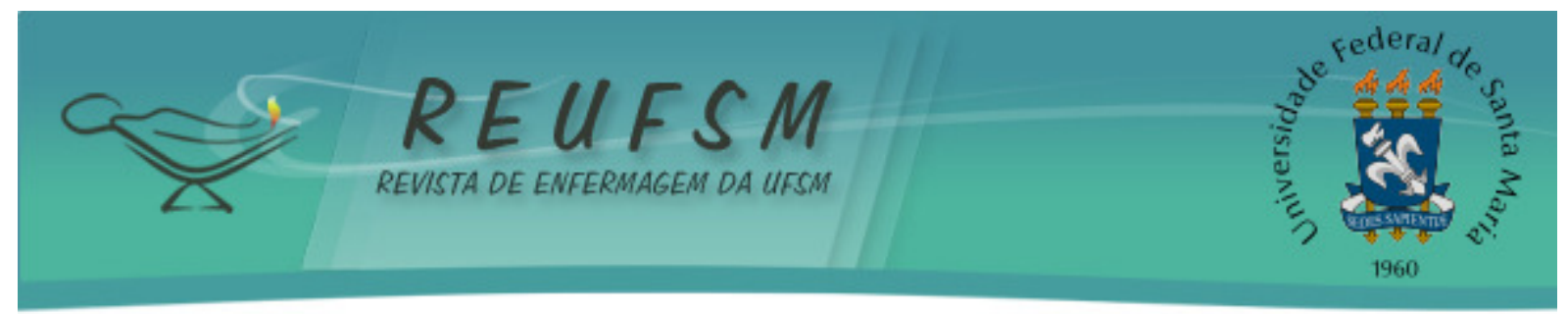

Diante desse contexto, para além das questões geracionais e migratórias, o estudo traz achados importantes e inovadores sobre a multiculturalidade, conflitos e simbolismos de cada mulher na construção da experiência de amamentar, revelando a necessidade e importância da cultura de origem/acolhimento, do apoio e do aprendizado, muitos dos quais estão centrados na presença da mãe, amigos, parceiro, mas também da mídia e das(os) profissionais de saúde, especialmente das(os) enfermeiras(os).

Desse modo, um estudo intergeracional e migratório sobre a amamentação, ancorado na TRS pode contribuir para que as(os) enfermeiras(os) possam desenvolver um cuidado baseado na singularidade e subjetividade das mulheres migrantes, respeitando as suas diversidades culturais e geográficas, diminuindo, assim, as múltiplas vulnerabilidades sociais. ${ }^{25}$

\section{CONCLUSÃO}

Nota-se que a amamentação para as migrantes permanece atrelada ao caráter instintivo e obrigatório da maternidade, revelado a partir da TRS. Para estas mulheres, aleitar representa um ato de amor, abnegação, proteção à saúde física e emocional do filho, mesmo que algumas tenham a vivenciado com dificuldades.

No que se refere ao processo de aprendizado sobre a amamentação, as mulheres migrantes representam a figura materna como núcleo central somado às experiências das avós. Elas justificam essa percepção pela proximidade afetiva, relação hierárquica no seio familiar e coabitação entre as gerações.

Além disso, as(os) profissionais de saúde atuam como incentivadoras(es) da amamentação, juntamente com a influência midiática e outros familiares, a exemplo dos pais das migrantes e dos seus respectivos maridos. Dessa forma, percebe-se que as representações sociais de apoio e ajuda, durante o aleitar, transitam nos diferentes gêneros.

Nesse sentido, torna-se necessário ampliar a rede de apoio à amamentação entre mulheres migrantes, considerando os aspectos da aculturação, decorrentes do deslocamento geográfico e/ou afetivo. Dessa forma, as limitações do estudo centraram-se na escassez de pesquisas nacionais e internacionais sobre o tema com enfoque no fluxo migratório e na coexistência de três gerações. Contudo, tais limitações não constituíram impedimento para validar os resultados da pesquisa, em decorrência da representatividade teórica elaborada pelas pesquisadoras. 


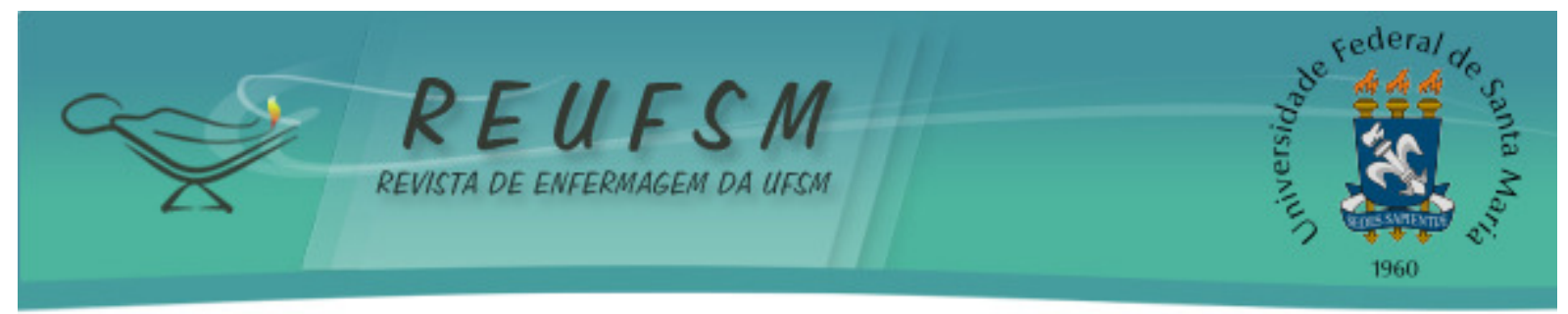

Destaca-se ainda que a pesquisa aponta diferenças com outros estudos na medida em que evidencia a relação de poder e afeto de mulheres mais velhas no que tange às mais jovens, interferindo nos simbolismos históricos e sociais sobre a amamentação. Além disso, a valorização do parceiro e das amigas como integrantes da rede de apoio na prática de amamentar começa a emergir como elemento imprescindível.

Ressalta-se que esse estudo pode trazer novas implicações como o desenvolvimento de pesquisas que associem migração, amamentação e intergeracionalidade na modalidade internacional. Assim, entende-se que será possível ampliar o entendimento dessa prática como um ato sociocultural, que sofre modificações em tempos e espaços geográficos distintos com interferência de familiares e profissionais da saúde.

Depreende-se, a partir desse estudo, que as simbologias das mulheres ancoram-se na amamentação como uma prática de nutrição, amor, benevolência e doação da mãe com o filho, com vistas ao desenvolvimento saudável. Para tanto, as migrantes de diferentes gerações utilizam do aporte cultural sobre a amamentação em diferentes locais e épocas, fazendo-as extrair conhecimento, por meio da mídia e atuação das(os) profissionais de saúde.

Tal pesquisa possibilita embasamento teórico para refletir sobre as ações em saúde voltadas à amamentação, a exemplo das rodas de conversas, palestras, cursos e consultas, principalmente aquelas desenvolvidas por enfermeiras(os), que abarcam esta prática com enfoque apenas no individual, desconsiderando os conhecimentos de outras mulheres da mesma família que podem influenciar nesse processo. Este estudo permite que os profissionais de saúde conheçam as representações sociais de mulheres migrantes na modalidade intermunicipal e interestadual e possam atuar sobre as construções culturais e geracionais com inserção gradativa dos familiares, tornando essa prática benéfica para mães, filhos, família e sociedade.

Por fim, reforça-se a participação da(o) enfermeira(o) como principal incentivador(a) no processo de amamentar das mulheres migrantes, visto que revela a importância da Enfermagem como uma ciência que alia conhecimento empírico e científico, que compreende os diversos saberes, que aproxima diferentes gerações em busca de um aprendizado que desmitifica tabus e crenças. 


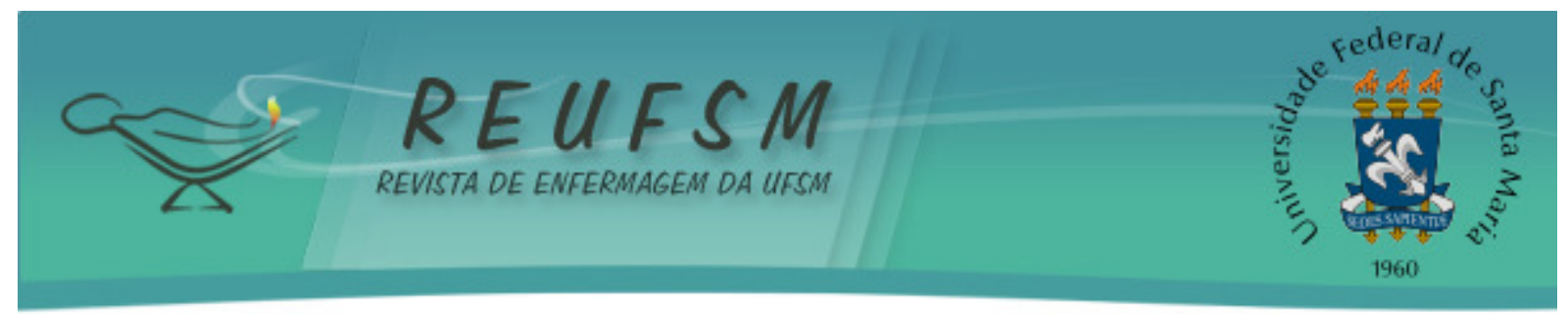

\section{REFERÊNCIAS}

1. Prates LA, Schmalfuss JM, Lipinski JM. Amamentação: a influência familiar e o papel dos profissionais de saúde. Rev Enferm UFSM [Internet]. 2014 abr-jun [acesso em 2016 abr 10];4(2):359-63. Disponível em: http://periodicos.ufsm.br/reufsm/article/view/10631/pdf.

2. Rodrigues JM, Oliveira TD, Soares GFG. Análise de gênero sobre as práticas de amamentação de três gerações: avó-filha-neta. Pensar Acadêmico [Internet]. 2016 jul-dez [acesso em 2016 jun 12];14(2):91-9. Disponível em: http://pensaracademico.facig.edu.br/index.php/pensaracademico/article/view/21/19.

3. Cremonese L, Wilhelm LA, Prates LA, Possati AB, Scarton J, Ressel LB. A decisão de amamentar durante a adolescência: um estudo na perspectiva cultural. Rev Enferm UFSM [Internet]. 2016 jul-set [acesso em 2016 abr 10];6(3):317-26. Disponível em: http://periodicos.ufsm.br/reufsm/article/view/19248/pdf.

4. Figueiredo MCD, Bueno MP, Ribeiro CC, Lima PA, Silva IT. Banco de leite humano: o apoio à amamentação e a duração do aleitamento materno exclusivo. Rev Bras Crescimento Desenvolv Hum [Internet]. 2015 jul [acesso em 2016 jan 05];25(2):204-10. Disponível em: http://pepsic.bvsalud.org/pdf/rbcdh/v25n2/pt_11.pdf.

5. Primo CC, Dutra PR, Lima EFA, Alvarenga SC, Leite FMC. Redes sociais que apoiam a mulher durante a amamentação. Cogitare Enferm [Internet]. 2015 abr-jun [acesso em 2016 jan 05];20(2):426-33. Disponível em: http://revistas.ufpr.br/cogitare/article/view/37453.

6. Ribeiro HMCB, Lamy ZC, Coimbra LC, Rocha LJLF, Aquino DMC, Coutinho NPS, Costa LFA, et al. Representações sociais de profissionais de núcleos de apoio à saúde da família sobre interdisciplinaridade. Trab Educ Saúde [Internet]. 2015 set-dez [acesso em 2017 set 16];13 Supl 2:97-115. Disponível em: http://www.scielo.br/pdf/tes/v13s2/1981-7746-tes-13s2-0097.pdf.

7. Pinto ER. Conceitos fundamentais dos métodos projetivos. Ágora [Internet]. 2014 jan-jun [acesso em 2016 abr 10];17(1):135-53. Disponível em: http://www.scielo.br/pdf/agora/v17n1/a09v17n1.pdf.

8. Viana RAA, Ferreira EG, Barboza MCC, Sampaio LMA. Aleitamento materno: desmistificando esse ato de amor como uma abordagem na promoção da saúde. Rev ABENO [Internet]. 2014 jan-jun [acesso em 2016 jan 05];14(1):38-46. Disponível em: https://revabeno.emnuvens.com.br/revabeno/article/view/83/104.

9. Brecailo MK, Tamanini M. Amamentar, cuidar, maternar: regulações, necessidades e subjetividades. Demetra [Internet]. 2016 jul-set [acesso em 2016 abr 15];11(3):825-46. Disponível em: http://www.epublicacoes.uerj.br/index.php/demetra/article/view/22507/18428\#.WRHVh_nyvIU.

10. Oliveira ED. Migração, identidade cultural e história oral: percurso possível de pesquisas. Monções [Internet]. 2015 out-mar [acesso em 2016 abr 15];2(2):170-80. Disponível em: http://seer.ufms.br/index.php/moncx/article/view/680/479.

11. Teixeira MA, Ribeiro LVB. As duas faces de uma mesma moeda: significados da amamentação para mães-nutrizes e suas amigas e/ou vizinhas. Rev Saúde Públ Santa Cat 


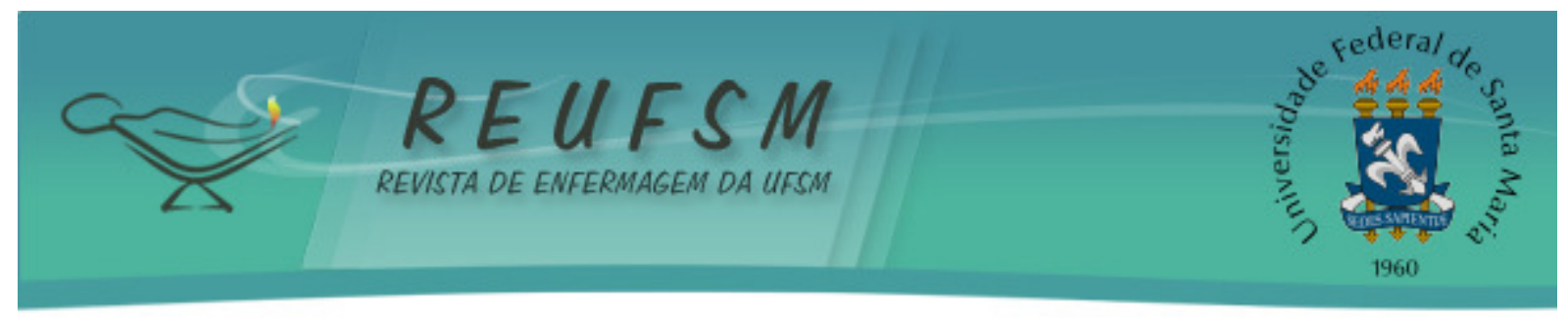

[Internet]. 2014 jan-abr [acesso em 2016 abr 10];7(1):48-63. Disponível em: http://esp.saude.sc.gov.br/sistemas/revista/index.php/inicio/article/viewFile/233/245.

12. Amaral LJX, Sales SS, Carvalho DPSRP, Cruz GKP, Azevedo IC, Ferreira Júnior MA. Fatores que influenciam na interrupção do aleitamento materno exclusivo em nutrizes. Rev Gaúch Enferm [Internet]. 2015 out [acesso em 2016 abr 05];36(spe):127-34. Disponível em: http://www.scielo.br/pdf/rgenf/v36nspe/0102-6933-rgenf-36-spe-0127.pdf.

13. Topa J, Neves S, Nogueira C. Imigração e saúde: a (in)acessibilidade das mulheres imigrantes aos cuidados de saúde. Saúde Soc [Internet]. 2013 abr-jun [acesso em 2016 jan 05];22(2):328-41. Disponível em: http://www.scielo.br/pdf/sausoc/v22n2/v22n2a06.pdf.

14. Martins MZO, Santana LS. Benefícios da amamentação para saúde materna. Interfaces Científicas - Saúde e Ambiente [Internet]. 2013 jun [acesso em 2016 jun 05];1(3):87-97. Disponível em: https://periodicos.set.edu.br/index.php/saude/article/view/763/443.

15. Teixeira MM, Vasconcelos VM, Silva DMA, Martins EMCS, Martins MC, Frota MA. Percepções de primíparas sobre orientações no pré-natal acerca do aleitamento materno. Rev Rene [Internet]. 2013 jan-mar [acesso em 2016 abr 10];14(1):179-86. Disponível em: http://www.periodicos.ufc.br/index.php/rene/article/view/3353/2591.

16. Ramos N. Interculturalidade(s) e mobilidade(s) no espaço europeu: viver e comunicar entre culturas[Internet]. In: Pina H, Martins F, Ferreira C, editores. The Overarching Issues of the European Space. Porto: Faculdade Letras Universidade do Porto; 2013 jan [acesso em 2016 abr 10];1(1):343-60. Disponível em: http://ler.letras.up.pt/uploads/ficheiros/12349.pdf. P. 343-60.

17. Moreira MA, Nascimento ER. Representações sociais sobre amamentação entre mulheres de três gerações: um estudo com desenho-estória temático. Rev Enferm UFPE Online [Internet]. 2013 jul [acesso em 2016 abr 12];7(7):4589-96. Disponível em: http://www.revista.ufpe.br/revistaenfermagem/index.php/revista/article/download/4703/6517.

18. Moreira MA, Nascimento ER, Paiva MS. Representações sociais de mulheres de três gerações sobre práticas de amamentação. Texto \& Contexto Enferm [Internet]. 2013 abr-jun [acesso em 2016 abr 10];22(2):432-41. Disponível em: http://www.scielo.br/pdf/tce/v22n2/v22n2a20.pdf.

19. Marin AH, Martins GDF, Freitas APCO, Silva IM, Lopes RCS, Piccinini CA. Transmissão intergeracional de práticas educativas parentais: evidências empíricas. Psicol Teor Pesqui [Internet]. 2013 abr-jun [acesso em 2016 jan 10];29(2):123-32. Disponível em: http://periodicos.unb.br/index.php/revistaptp/article/view/20893/14945.

20. Motta-Gallo S, Gallo P, Cuenca A. Influência da televisão nos hábitos alimentares de crianças do nordeste brasileiro. Rev Bras Crescimento Desenvolv Hum [Internet]. 2013 janmar [acesso em 2016 jun 10];23(1):87-93. Disponível em: http://www.revistas.usp.br/jhgd/article/view/50396/54515.

21. Moreira LA, Cruz NV, Linhares FMP, Guedes TG, Martins FDP, Pontes CM. Apoios à mulher/nutriz nas peças publicitárias da Semana Mundial da Amamentação. Rev Bras Enferm [Internet]. 2017 jan-fev [acesso em 2017 abr 05];70(1):61-70. Disponível em: http://www.scielo.br/pdf/reben/v70n1/0034-7167-reben-70-01-0061.pdf. 


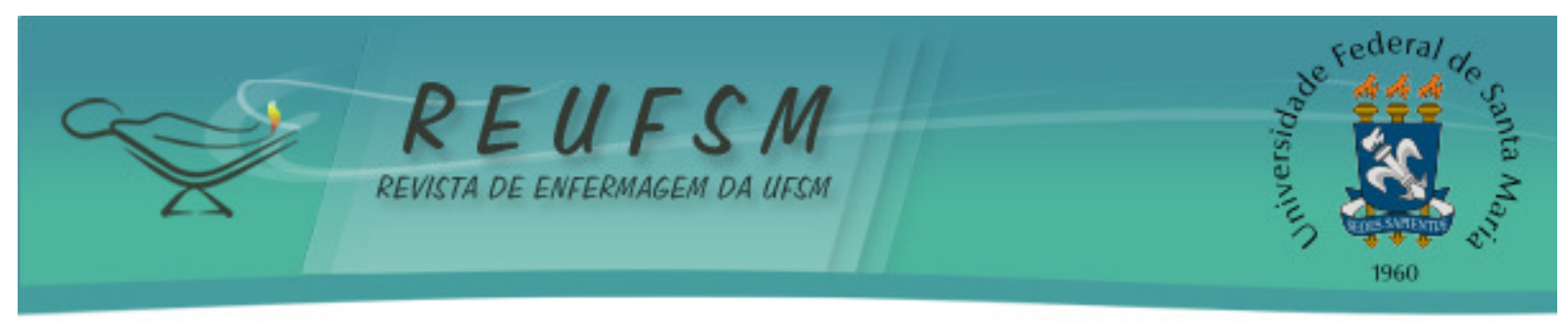

22. Valença TDC, Santos WS, Lima PV, Santana ES, Reis LA. Deficiência física na velhice: um estudo estrutural das representações sociais. Esc Anna Nery Rev Enferm [Internet]. 2017 jan [acesso em 2017 abr 15];21(1):1-8. Disponível em: http://www.scielo.br/pdf/ean/v21n1/1414-8145-ean-21-01-e20170008.pdf.

23. Mazza VA, Nunes RCT, Tararthuch RZP, Alexandre AMC, Patel JV. Influência das redes sociais de apoio para nutrizes adolescentes no processo de amamentação. Cogitare Enferm [Internet]. 2014 abr-jun [acesso em 2016 jan 10];19(2):254-60. Disponível em: http://revistas.ufpr.br/cogitare/article/view/36975/22730.

24. Lima LS, Souza SNDH. Percepção materna sobre o apoio recebido para a amamentação: o olhar na perspectiva da vulnerabilidade programática. Semina [Internet]. 2013 jan-jul [acesso em 2016 jan 10];34(1):73-90. Disponível em: http://www.uel.br/revistas/uel/index.php/seminabio/article/view/12595/13738.

25. Ferreira, MA. Teoria das representações sociais e contribuições para as pesquisas do cuidado em saúde e de enfermagem. Esc Anna Nery Rev Enferm [Internet]. 2016 abr-jun [acesso em 2017 set 16];20(2):214-9. Disponível em: http://www.scielo.br/pdf/ean/v20n2/1414-8145-ean-20-02-0214.pdf.

Data de submissão: 05/04/2017

Data de aceite: $20 / 10 / 2017$

Autor correspondente: Michelle Araújo Moreira

Endereço: Avenida Lomanto Junior, nº 500, Edifício Baía Marina Residence, apt ${ }^{\circ}$ 406, Pontal, Ilhéus-Bahia.

CEP: 45.654-000

Email: michelleepedro@uol.com.br 